\title{
25 Research Soure \\ Effect of Spectral CT on Tumor Microvascular Angiogenesis in Renal Cell Carcinoma
}

\author{
Bei Zhang \\ First Hospital of Jilin University \\ Qiong Wu \\ First Hospital of Jilin University \\ Xiang Qiu \\ First Hospital of Jilin University \\ Xiaobo Ding \\ First Hospital of Jilin University \\ Jin Wang \\ First Hospital of Jilin University \\ Jing Li \\ First Hospital of Jilin University \\ Pengfei Sun \\ First Hospital of Jilin University \\ Xiaohan Hu ( $\nabla$ xhhu@jlu.edu.cn) \\ First Hospital of Jilin University
}

\section{Research Article}

Keywords: angiogenesis, dual-energy CT, renal cell carcinoma, microvessel angiogenesis, quantitative imaging

Posted Date: April 26th, 2021

DOI: https://doi.org/10.21203/rs.3.rs-398147/v1

License: @ (i) This work is licensed under a Creative Commons Attribution 4.0 International License. Read Full License

Version of Record: A version of this preprint was published at BMC Cancer on July 30th, 2021. See the published version at https://doi.org/10.1186/s12885021-08586-x. 


\section{Abstract}

Background: To examine the value of spectral CT quantitative parameters in renal cell carcinoma (RCC) microvascular angiogenesis.

Methods: The authors evaluated 32 patients with pathologically confirmed RCC who underwent triple-phase contrast-enhanced CT with spectral CT imaging mode from January 2017 to December 2019. Quantitative parameters including the parameters derived from iodine concentration (IC) and water concentration (WC) of $120 \mathrm{keV}$ monochromatic images. The microvascular density (MVD), microvascular area (MVA) and etc. al. of specimens were evaluated. The correlation between IC and WC (including average values and random values) with microvascular parameters were analyzed using Pearson or Spearman rank correlation coefficients.

Results: The MVD of all tumors was 26.00 (15.00-43.75) vessels per field at $\times 400$ magnification. The MVD of RCC correlated positively with the mean IC, mean WC, mean NWC, mean NIC, random IC, random NIC in renal cortical phase, $W_{C D}, W_{2}, D_{2}, C_{2}$ and $I_{C D}$ (Spearman rank correlation coefficients, $r$ range $0.362-0.533$; all $p<0.05)$. The MVA of all tumors was $(16.16 \pm 8.98) \%$ per field at $\times 400$ magnification. The MVA of RCC correlated positively with the mean IC, mean WC, mean NWC, mean NIC, random IC, random NIC in renal cortical, mean WC and mean NWC in renal parenchymal phase, WCD,$W^{2} D_{2}$, WCD 3 , NWCD and $\mathrm{NWCD}_{3}$ (Pearson or Spearman rank correlation coefficients, $r$ range, $0.357-0.576$; all $p<0.05$ ). Microvascular grading correlated positively with the mean NWC, mean NIC and random NIC in renal cortical phase, mean NWC in renal parenchymal phase, NWCD $, W_{3}, \mathrm{NWCD}_{3}, \mathrm{NICD}_{2}$ and NICD $3\left(\mathrm{Spearman}_{3}\right.$ rank

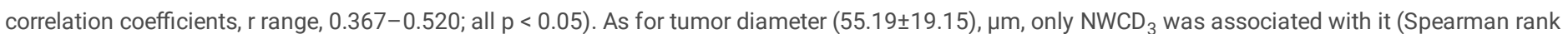
correlation coefficients, $r=0.388 ; p<0.05)$.

Conclusions: IC and WC indexes derived from spectral CT, especially the renal cortical phase, difference between renal cortical phase and parenchymal phase were useful indicators for evaluating tumor angiogenesis. Moreover, the difference of the derived parameters of WC in different phases has stronger correlation with tumor angiogenesis than that of IC.

\section{Introduction}

Renal cell carcinoma (RCC) is a kind of tumor originated from renal epithelial cells, accounting for more than $90 \%$ of renal cell carcinoma, which accounts for $2 \%$ of adult malignancies[1,2]. Clear cell renal cell carcinoma (ccRCC) is the most common subtype[3]. Due to the formation of new microvessels, the structure of microvessels in malignant tumors is different from that in normal tumors. In malignant tumors, microvessels are curved and organized more irregularly. Moreover, their walls are more fragile because of the weak connection between endothelial cells and other pericyte layers, as well as basement membrane[4]. These characteristics are related to the susceptibility of tumor invasion, metastasis and recurrence.

Microvessel density (MVD) and microvessel area (MVA) measured by immunohistochemical technique have been considered as the criteria for evaluating tumor angiogenesis, which reflect the intensity of blood vessels, the area of endothelial lumen and the blood volume for tumor perfusion[5, 6]. However, studies on different types of solid tumors show that MVD and MVA are negatively correlated with survival rate, directly correlated or no significant difference[7]. The reasons for these contradictory findings are not completely clear. CT and MR perfusion imaging, as well as intravoxel incoherent motion (IVIM) model for diffusion weighted, were once considered to be ideal for preoperative noninvasive evaluation of tumor angiogenesis[8]. However, due to the large radiation dose, long examination time and other factors, they are limited in clinical application.

In recent years, spectral imaging has been introduced as a new application of dual energy CT and the advanced CT scanning technology[9]. Spectral CT can provide iodinebased material decomposition image and quantitatively analyze the iodine concentration (IC) of normal tissues and lesions in enhanced images. IC has a certain value in the imaging diagnosis, pathological grading and differential diagnosis of RCC[10, 11]. However, only a few studies focused on the relationship between IC derived from spectral CT and RCC angiogenesis. Therefore, it is of great significance to explore the expression of IC and WC on the angiogenesis of tumor. The purpose of this study was to analyze the relationship between IC and WC with RCC angiogenesis.

\section{Materials And Methods}

\section{Participants}

The study was approved by the Institutional Ethics Committee of the First Hospital of Jilin University, Changchun, China. Written informed consent was obtained from the patients by email or letter. We retrospectively reviewed the Picture Archiving and Communication System for renal cell carcinoma patients who had undergone renal CT plain scan plus three-phase enhancement before surgery (January 2017 to December 2019). The inclusion criteria were as follows: 1) patients aged between 18 and 80 years; 2) renal CT plain scan plus three-phase enhancement before surgery; 3 ) patients who had undergone CT performed according to our standard MM protocol; 4) patients who had received standard nephrectomy; 5) There is an interval between CT scan and surgery and the interval was no more than 2 weeks.

The exclusion criteria were as follows: 1) patients with renal cell carcinoma complicated with hemorrhage were excluded; 2) Imaging data with poor quality due to body movements or other artifacts.

\section{Energy Spectrum CT Imaging}

Renal three-phase enhancement CT were performed on a Revolution GSI CT scanner (GE Healthcare). Scanning range was conducted from "diaphragmatic apex to lower pole of kidney" with supine position. The CT scan was conducted with the following parameters: tube voltage, automatically selected by the machine according to the patient's weight; tube current, $485 \mathrm{~mA}$; pitch, 0.984; field of view (FOV), medium; image matrix,512×512; rotation speed, 0.6; slice thickness/gap, 5/5mm. Renal three-phase enhancement scan: high pressure syringe was used to inject non-ionic contrast agent iohexol or iopatol through

Page $2 / 13$ 
elbow vein, with the dosage of $1.0-1.5 \mathrm{ml} / \mathrm{kg}$ and the speed of $3.5 \mathrm{ml} / \mathrm{s}$. The cortical phase scanning was performed at $25 \mathrm{~s}$ after injection, renal parenchymal phase scanning was performed at $(60 \pm 5)$ s, and excretion phase scanning was performed at $(180 \pm 30) s$ after injection. During the scanning, the patient was asked to hold his breath after deep inspiration to avoid motion artifacts affecting the image quality.

\section{Acquisition of iodine and water concentration}

The iodine and water concentration of renal three-phase enhancement CT were measured in Picture Archiving and Communication Systems (Neusoft, Version 5.5, China). The IC of each tumor needs to take the average of six values on the decomposition images for iodine (120kev). These six values include four values in the axial maximum plane and two values in the coronal maximum plane. The four measurement values of the maximum axial plane include the measurement values of the front, back, left and right directions, and the region of interest (ROI) of these four directions should not cross each other as far as possible, and avoid obvious necrosis. And keep the area of ROI consistent. The WC of each tumor was obtained on the water equivalent images in the same way as above. The iodine concentration in the aorta $\left(\mathrm{IC}_{\mathrm{ao}}\right)$ at the same slice of the lesion was obtained. Normalized iodine concentration (NIC) was normalized

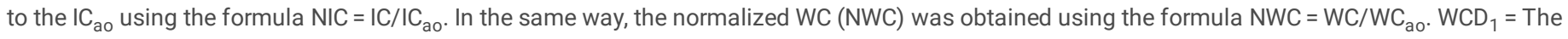
difference of WC between renal cortical phase and parenchymal phase. NWCD ${ }_{1}=$ The difference of NWC between renal cortical phase and parenchymal phase. $W C D_{2}=$ The difference of WC between renal parenchymal phase and excretory phase. $N W C D_{2}=$ The difference of NWC between renal parenchymal phase and excretory phase. $W_{C D}=$ The difference of WC between renal cortical phase and excretory phase. $N W C D_{3}=T$ The difference of NWC between renal cortical phase and excretory phase. ICD $1=$ The difference of IC between renal cortical phase and parenchymal phase. NICD $=$ The difference of NIC between renal cortical phase and parenchymal phase. $I C D_{2}=$ The difference of IC between renal parenchymal phase and excretory phase. $N I C D_{2}=T$ The difference of $N I C$ between renal parenchymal phase and excretory phase. $I C D_{3}=$ The difference of $I C$ between renal cortical phase and excretory phase. $N I C D_{3}=T$ the difference of NIC between renal cortical phase and excretory phase.

\section{Interpretation of clinicopathological results}

According to the electronic medical records, the pathologic findings such as tumor types, tumor classifications, and stage of tumor were assessed. Distant metastasis was defined by imaging examinations and clinical follow-up[12].

\section{Immunohistochemical analysis}

Immunohistochemistry was used to stain tumor microvessels. The first antibody was CD34. The thickness of paraffin fixed sections was $5 \mu$ m, which were dewaxed and hydrated. Microwave antigen repair, $2 \%$ citrate buffer, $\mathrm{PH} 6.0,15 \mathrm{~min}$. After the first antibody was dripped, the slices were incubated in a wet box at $4{ }^{\circ} \mathrm{C}$ overnight. After the universal second antibody was dripped, the slices were placed in a wet box and incubated at $37{ }^{\circ} \mathrm{C}$ for 30 min. The slices were washed with TBS $(0.01 \mathrm{~mol} / \mathrm{L}, \mathrm{pH} 7.4)$ for 3 times. After DAB staining, the nuclei were stained with hematoxylin. Finally, seal the slide.

\section{Analysis of tumor microvessels}

Five sections per patient, and the average value of microvessel density, area and grading was taken from the five sections. When no less than one slice has characteristic blood vessels, the characteristic blood vessels can be defined as positive.

1) Microvessel density (MVD): After staining, the high vascular density area was found under low power microscope. The top five regions with the higher vascular density in each slice were selected. The number of microvessels in each field of vision was counted. The average value of the five regions is calculated as MVD. When counting, only a single endothelial cell or cell cluster is counted, otherwise the vascular lumen is not counted as microvessel.

2) Microvascular area (MVA): Percentage of microvessel area in tumor tissue area.

3) Microvascular classification: Punctiform microvessels showed that the microvessels were divided by tumor cells and distributed in punctiform shape, and there was no communication between the microvessels. The linear microvessel showed that there were punctate microvessels on both sides of the microvessel, and the middle was long and narrow, which was linear. The annular microvessels are characterized by thick microvessels, which encircle the tumor cells in an island shape and communicate with each other. Strip type microvessels showed thick microvessels, parallel to tumor trabeculae, communicating with each other, showing a thick network. The tumor microvascular classification was semi quantified: the punctiform type was grade I, the linear type was grade II, and the annular or strip type was grade III. The microvascular grade of the tumor was based on the majority of the grading results in any 10 high-power fields.

4) Analysis of special vascular structure: Record whether there are vascular lakes, vascular trees (One main vessel accompanied by branch vessels), thick muscular vessels and vessels with diameter more than 50 microns appearing.

\section{Statistical analysis}

Pearson's or Spearman's correlation test was used to test the correlation between WC and IC values (mean WC, mean IC, random WC, random IC, mean NWC and mean NIC in renal cortical phase, parenchymal phase and excretory phase; WCD, NWCD, DIC and NICD parameters) with microvessel parameters (MVD, MVA, specific microvascular, microvascular grading, vessel diameter and tumor diameter). All statistical analyses were performed using SPSS 21.0 (SPSS). P $<0.05$ was considered statistically significant.

\section{Results}


Demographic and Relevant Characteristics

A total of 32 patients with RCC were included in the study. Table 1 shows their demographic, pathological microvascular data and values of iodine and water concentration in three phase enhancement. RCC in this study affected men more often than women. Most of the measurement data accord with normal distribution, only a few (MVD, NMWC in renal cortical phase, NMIC in renal excretory phase, RIC in renal cortical phase, ICD $1, I_{2}, D_{2} I_{C D}, N I C D_{3}, N W C D_{2}$ and $\mathrm{NWCD}_{3}$ ) are skew distribution. 
Table 1

Demographic and clinical characteristics

\section{Variable}

Age (years)

Male/Female

MWC/MNWC (mg/ml)

Renal cortical phase

Renal parenchymal phase

Renal excretory phase

\section{RWC/RNWC (mg/ml)}

Renal cortical phase

Renal excretory phase

\section{$\mathrm{MIC} / \mathrm{MNIC}(\mathrm{mg} / \mathrm{ml})$}

Renal cortical phase

$28.99 \pm 14.52$

$0.33 \pm 0.14$

Renal parenchymal phase

$24.65 \pm 8.37 /$

$0.71 \pm 0.23$

Renal excretory phase

$17.09 \pm 6.60 /$

$0.91(0.78-1.05)$

$\mathrm{RIC/RNIC} \mathrm{(mg/ml)}$

Renal cortical phase

Renal parenchymal phase

$27.00(19.50-34.25) /$

$0.32 \pm 0.16$

$24.16 \pm 8.86 /$

$0.70 \pm 0.27$

Renal excretory phase

$16.95 \pm 5.49 /$
$0.79 \pm 0.27$

Data are expressed as mean \pm standard deviation, median (interquartile range) or $n(\%) . M V D=$ microvessel density, $M V A=$ microvessel area. $\mathrm{WCD}_{1}=\mathrm{The}$ difference of mean WC in renal cortical phase and parenchymal phase, NWCD ${ }_{1}=$ The difference of mean NWC in renal cortical phase and parenchymal phase, $W_{C D}=$ The difference of mean WC in renal cortical and parenchymal phase, $\mathrm{NWCD}_{2}=$ The difference of mean NWC in renal cortical and parenchymal phase, $\mathrm{WCD}_{3}=$ The difference of mean WC in renal parenchymal phase and excretory phase, $\mathrm{NWCD}_{3}=\mathrm{The}_{\mathrm{C}}$ difference of mean NWC in renal parenchymal phase and excretory phase. $I C D_{1}=$ The difference of mean IC in renal cortical phase and parenchymal phase, $N I C D_{1}=T$ The difference of mean $\mathrm{NIC}$ in renal cortical phase and parenchymal phase, $I \mathrm{ICD}_{2}=$ The difference of mean WC in renal cortical and parenchymal phase, NICD $=T$ The difference of mean NIC in renal cortical and parenchymal phase, $I_{C D}=$ The difference of mean WC in renal parenchymal phase and excretory phase, $\mathrm{NICD}=\mathrm{The}$ difference of mean NIC in renal parenchymal phase and excretory phase. 


\begin{tabular}{|c|c|}
\hline Variable & Patients $(n=32)$ \\
\hline \multirow[t]{2}{*}{$\mathrm{WCD}_{1} / \mathrm{NWCD}_{1}(\mathrm{mg} / \mathrm{ml})$} & $12.87 \pm 21.26 /$ \\
\hline & $-0.30 \pm 0.13$ \\
\hline \multirow[t]{2}{*}{$\mathrm{WCD}_{2} / \mathrm{NWCD}_{2}(\mathrm{mg} / \mathrm{ml})$} & $30.24 \pm 27.82 /$ \\
\hline & $-0.40[-0.46-(-0.30)]$ \\
\hline \multirow[t]{2}{*}{$\mathrm{WCD}_{3} / \mathrm{NWCD}_{3}(\mathrm{mg} / \mathrm{ml})$} & $17.37 \pm 13.38 /$ \\
\hline & $-0.12(-0.22-0.02)$ \\
\hline \multirow[t]{2}{*}{$\mathrm{ICD}_{1} / \mathrm{NICD}_{1}(\mathrm{mg} / \mathrm{ml})$} & $4.14(-2.91-8.17) /$ \\
\hline & $-0.388 \pm 0.15$ \\
\hline \multirow[t]{2}{*}{$\mathrm{ICD}_{2} / \mathrm{NICD}_{2}(\mathrm{mg} / \mathrm{ml})$} & $13.17(2.18-16.34) /$ \\
\hline & $-0.56[-0.75-(-0.42)]$ \\
\hline \multirow[t]{2}{*}{$\mathrm{ICD}_{3} / \mathrm{NICD}_{3}(\mathrm{mg} / \mathrm{ml})$} & $7.56 \pm 4.92 /$ \\
\hline & $-0.21[-0.36-(-0.05)]$ \\
\hline \multicolumn{2}{|l|}{ Microvascular grading } \\
\hline II & $15(46.9 \%)$ \\
\hline III & $17(53.1 \%)$ \\
\hline MVD & $26.00(15.00-43.75)$ \\
\hline MVA(\%) & $16.16 \pm 8.98$ \\
\hline Microvascular diameter $(\mu \mathrm{m})$ & $20.63 \pm 9.73$ \\
\hline Tumor diameter $(\mu \mathrm{m})$ & $55.19 \pm 19.15$ \\
\hline Microvascular diameter/ Tumor diameter (\%) & $40.98 \pm 19.66$ \\
\hline \multicolumn{2}{|c|}{ 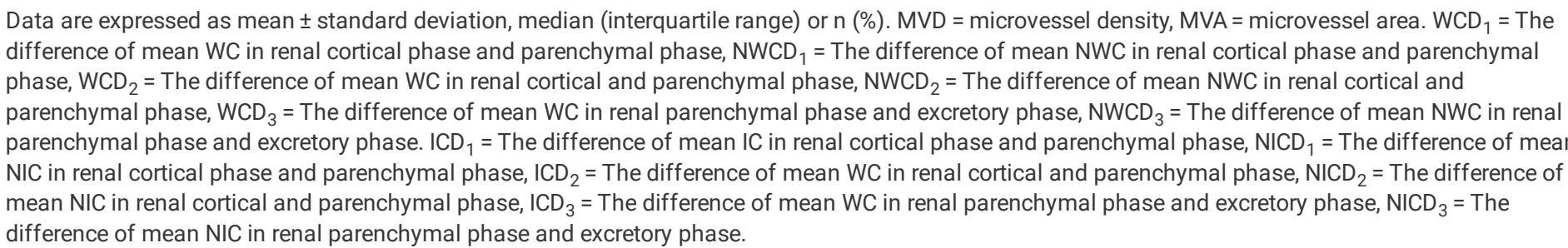 } \\
\hline
\end{tabular}

\section{Imaging Data}

\section{Correlation between microvessel parameters and WC/IC in renal cortical phase}

The correlations between the WC/IC in renal cortical phase and microvessel parameters were analyzed. The mean WC, mean IC, mean NWC, mean NIC, random IC and random NIC from renal cortical phase scanning correlated positively with the MVD of RCC (Spearman rank correlation coefficients, all $p<0.05$ ), as shown in Table 2. In the same scanning phase, the correlations between the mean NIC and mean NWC with MVD were better than those between the mean IC and mean WC with MVD. Moreover, for the same phase, the correlations between the mean IC and mean NIC with MVD were stronger than those between the random IC and random NIC with MVD. The mean WC, mean IC, mean NWC, mean NIC, random IC and random NIC from renal cortical phase scanning correlated positively with the MVA of RCC (Pearson or Spearman rank correlation coefficients, all $p<0.05$ ), as shown in Table 2 . In the same scanning phase, the correlations between the mean IC and mean NWC with MVA were better than those between the mean NIC and mean WC with MVA. Moreover, for the same phase, the correlations between the mean IC and mean NIC with MVA were stronger than those between the random IC and random NIC with MVA. The mean NWC, mean NIC and random NIC had moderate positive correlation with microvascular grading (Spearman rank correlation coefficients, all $p<0.05$ ), and the correlation between the mean NIC and microvascular grading was stronger than that between the mean NWC with microvascular grading. 
Table 2

Linear regression results evaluating the correlation of microvessel parameters and WC/IC in renal cortical phase

\begin{tabular}{|c|c|c|c|c|c|c|c|c|c|c|c|c|c|c|c|}
\hline \multirow{2}{*}{$\begin{array}{l}\text { Microvessel } \\
\text { Parameters }\end{array}$} & \multicolumn{2}{|c|}{ Mean WC } & \multicolumn{2}{|c|}{ Mean IC } & \multicolumn{2}{|c|}{ Mean NWC } & \multicolumn{2}{|c|}{ Mean NIC } & \multicolumn{2}{|c|}{ Random WC } & \multicolumn{2}{|c|}{ Random IC } & Random NWC & \multicolumn{2}{|c|}{ Randol } \\
\hline & $\mathbf{r}$ & $\begin{array}{l}\mathrm{P} \\
\text { value }\end{array}$ & $\mathbf{r}$ & $\begin{array}{l}\mathrm{P} \\
\text { value }\end{array}$ & $r$ & $\begin{array}{l}\mathrm{P} \\
\text { value }\end{array}$ & $\mathbf{r}$ & $\begin{array}{l}\mathrm{P} \\
\text { value }\end{array}$ & $\mathbf{r}$ & $\begin{array}{l}\mathrm{P} \\
\text { value }\end{array}$ & $\mathbf{r}$ & $\begin{array}{l}\mathrm{P} \\
\text { value }\end{array}$ & $\mathbf{r}$ & $\begin{array}{l}P \\
\text { value }\end{array}$ & $\mathbf{r}$ \\
\hline MVD & 0.362 & $0.042^{\star}$ & 0.421 & $0.016^{\star}$ & 0.524 & $0.002^{*}$ & 0.484 & $0.005^{\star}$ & 0.151 & 0.409 & 0.413 & $0.019 *$ & 0.287 & 0.112 & $0 . \AA$ \\
\hline MVA & 0.494 & $0.004^{*}$ & 0.477 & $0.006^{*}$ & 0.520 & $0.002^{*}$ & 0.469 & $0.007^{*}$ & 0.236 & 0.149 & 0.370 & $0.037 *$ & 0.293 & 0.104 & $0 . \AA$ \\
\hline $\begin{array}{l}\text { Specific } \\
\text { microvascular }\end{array}$ & 0.121 & 0.509 & 0.139 & 0.450 & 0.259 & 0.153 & 0.259 & 0.157 & 0.032 & 0.863 & 0.160 & 0.381 & 0.246 & 0.175 & 0.1 \\
\hline $\begin{array}{l}\text { Microvascular } \\
\text { grading }\end{array}$ & 0.214 & 0.240 & 0.281 & 0.119 & 0.448 & $0.010 *$ & 0.479 & $0.006^{*}$ & -0.031 & 0.868 & 0.285 & 0.114 & 0.156 & 0.393 & $0 .:$ \\
\hline $\begin{array}{l}\text { Vessel } \\
\text { diameter }\end{array}$ & 0.158 & 0.338 & 0.127 & 0.487 & 0.259 & 0.152 & 0.265 & 0.201 & 0.046 & 0.802 & 0.192 & 0.292 & 0.103 & 0.576 & $0 . c$ \\
\hline $\begin{array}{l}\text { Tumor } \\
\text { diameter }\end{array}$ & -0.242 & 0.182 & -0.242 & 0.181 & -0.013 & 0.943 & -0.127 & 0.490 & -0.190 & 0.298 & -0.307 & 0.087 & -0.075 & 0.684 & -0 . \\
\hline $\begin{array}{l}\text { Vessel } \\
\text { diameter/ } \\
\text { Tumor } \\
\text { diameter }\end{array}$ & 0.161 & 0.380 & 0.156 & 0.393 & 0.142 & 0.439 & 0.107 & 0.560 & 0.037 & 0.840 & 0.321 & 0.073 & 0.063 & 0.731 & $0 . c$ \\
\hline
\end{tabular}

*means that $\mathrm{P} \otimes 0.05$, with statistical significance.

\section{Correlation between microvascular parameters and WC/IC in renal parenchymal phase}

The relationships between microvascular parameters and WC/IC of renal parenchymal phase among the 32 patients enrolled in the study are presented in Table 3. The mean WC and mean NWC correlated positively with the MVA of RCC (Pearson rank correlation coefficients, both $p<0.05$ ). And even more the correlation between the mean NWC and MVA was slightly stronger than that between the mean WC with MVA. At the same time, the mean NWC was also found to be positively correlated with microvascular grading (Pearson rank correlation coefficients, $p<0.05$ ).

Table 3

Multiple linear regression results evaluating the correlation of microvessel parameters and WC/IC in renal parenchymal phase

\begin{tabular}{|c|c|c|c|c|c|c|c|c|c|c|c|c|c|c|c|}
\hline \multirow{2}{*}{$\begin{array}{l}\text { Microvessel } \\
\text { Parameters }\end{array}$} & \multicolumn{2}{|c|}{ Mean WC } & \multicolumn{2}{|c|}{ Mesn IC } & \multicolumn{2}{|c|}{ Mean NWC } & \multicolumn{2}{|c|}{ Mean NIC } & \multicolumn{2}{|c|}{ Random WC } & \multicolumn{2}{|c|}{ Random IC } & \multicolumn{2}{|c|}{ Random NWC } & \multirow{2}{*}{$\begin{array}{l}\text { Rand } \\
r\end{array}$} \\
\hline & $\mathbf{r}$ & $\begin{array}{l}P \\
\text { value }\end{array}$ & $\mathbf{r}$ & $\begin{array}{l}P \\
\text { value }\end{array}$ & $\mathbf{r}$ & $\begin{array}{l}P \\
\text { value }\end{array}$ & $\mathbf{r}$ & $\begin{array}{l}P \\
\text { value }\end{array}$ & $\mathbf{r}$ & $\begin{array}{l}P \\
\text { value }\end{array}$ & $\mathbf{r}$ & $\begin{array}{l}P \\
\text { value }\end{array}$ & $\mathbf{r}$ & $\begin{array}{l}P \\
\text { value }\end{array}$ & \\
\hline MVD & 0.158 & 0.387 & 0.221 & 0.225 & 0.284 & 0.115 & 0.227 & 0.211 & 0.120 & 0.513 & 0.118 & 0.520 & 0.179 & 0.326 & 0.130 \\
\hline MVA & 0.355 & $0.046^{*}$ & 0.336 & 0.060 & 0.363 & $0.041^{*}$ & 0.279 & 0.122 & 0.274 & 0.130 & 0.306 & 0.088 & 0.289 & 0.108 & 0.247 \\
\hline $\begin{array}{l}\text { Specific } \\
\text { microvascular }\end{array}$ & 0.014 & 0.938 & -0.023 & 0.900 & 0.055 & 0.765 & -0.072 & 0.695 & 0.064 & 0.730 & -0.169 & 0.355 & 0.061 & 0.742 & $-0.09 !$ \\
\hline $\begin{array}{l}\text { Microvascular } \\
\text { grading }\end{array}$ & 0.200 & 0.272 & 0.187 & 0.307 & 0.390 & $0.027 *$ & 0.200 & 0.272 & 0.268 & 0.138 & 0.163 & 0.373 & 0.326 & 0.069 & 0.234 \\
\hline $\begin{array}{l}\text { Vessel } \\
\text { diameter }\end{array}$ & -0.022 & 0.906 & -0.034 & 0.853 & 0.016 & 0.932 & -0.037 & 0.839 & -0.150 & 0.413 & -0.158 & 0.388 & -0.086 & 0.638 & $-0.14 !$ \\
\hline $\begin{array}{l}\text { Tumor } \\
\text { diameter }\end{array}$ & -0.122 & 0.508 & -0.175 & 0.339 & 0.041 & 0.822 & -0.117 & 0.522 & -0.083 & 0.650 & -0.204 & 0.263 & 0.056 & 0.761 & $-0.10<$ \\
\hline $\begin{array}{l}\text { Vessel } \\
\text { diameter/ } \\
\text { Tumor } \\
\text { diameter }\end{array}$ & -0.046 & 0.801 & -0.008 & 0.967 & -0.060 & 0.745 & 0.007 & 0.972 & -0.167 & 0.360 & -0.074 & 0.686 & -0.143 & 0.433 & -0.08 \\
\hline
\end{tabular}

Correlation between microvascular parameters and WC/IC in renal excretory phase

The correlations between the WC/IC indexes in renal excretory phase and microvascular parameters of RCC were shown in Table 4. There was no significant correlation between all WC / IC derived indicators and microvascular parameters (Pearson or Spearman rank correlation coefficients, all $\mathrm{p} \otimes 0.05$ ). 
Table 4

Multiple linear regression results evaluating the correlation of microvessel parameters and WC/IC in renal excretory phase

\begin{tabular}{|c|c|c|c|c|c|c|c|c|c|c|c|c|c|c|c|}
\hline \multirow{2}{*}{$\begin{array}{l}\text { Microvessel } \\
\text { Parameters }\end{array}$} & \multicolumn{2}{|c|}{ Mean WC } & \multicolumn{2}{|c|}{ Mesn IC } & \multicolumn{2}{|c|}{ Mean NWC } & \multicolumn{2}{|c|}{ Mean NIC } & \multicolumn{2}{|c|}{ Random WC } & \multicolumn{2}{|c|}{ Random IC } & \multicolumn{2}{|c|}{ Random NWC } & \multirow{2}{*}{$\begin{array}{l}\text { Randor } \\
\mathbf{r}\end{array}$} \\
\hline & $\mathbf{r}$ & $\begin{array}{l}P \\
\text { value }\end{array}$ & $\mathbf{r}$ & $\begin{array}{l}P \\
\text { value }\end{array}$ & $\mathbf{r}$ & $\begin{array}{l}P \\
\text { value }\end{array}$ & $\mathbf{r}$ & $\begin{array}{l}P \\
\text { value }\end{array}$ & $\mathbf{r}$ & $\begin{array}{l}P \\
\text { value }\end{array}$ & $\mathbf{r}$ & $\begin{array}{l}P \\
\text { value }\end{array}$ & $\mathbf{r}$ & $\begin{array}{l}P \\
\text { value }\end{array}$ & \\
\hline MVD & -0.095 & 0.606 & 0.215 & 0.237 & -0.035 & 0.850 & 0.137 & 0.455 & -0.042 & 0.819 & 0.272 & 0.132 & -0.026 & 0.889 & 0.137 \\
\hline MVA & 0.059 & 0.749 & 0.186 & 0.308 & 0.019 & 0.917 & -0.007 & 0.971 & 0.092 & 0.618 & 0.333 & 0.162 & 0.053 & 0.779 & -0.045 \\
\hline $\begin{array}{l}\text { Specific } \\
\text { microvascular }\end{array}$ & -0.156 & 0.394 & -0.032 & 0.863 & -0.298 & 0.098 & -0.159 & 0.385 & 0.001 & 0.994 & 0.023 & 0.900 & -0.084 & 0.648 & 0.159 \\
\hline $\begin{array}{l}\text { Microvascular } \\
\text { grading }\end{array}$ & -0.112 & 0.542 & 0.132 & 0.471 & -0.261 & 0.148 & -0.193 & 0.285 & 0.024 & 0.897 & 0.156 & 0.393 & -0.170 & 0.353 & -0.193 \\
\hline $\begin{array}{l}\text { Vessel } \\
\text { diameter }\end{array}$ & -0.303 & 0.092 & -0.062 & 0.735 & -0.246 & 0.175 & 0.137 & 0.455 & -0.245 & 0.177 & 0.068 & 0.710 & -0.207 & 0.255 & 0.151 \\
\hline $\begin{array}{l}\text { Tumor } \\
\text { diameter }\end{array}$ & -0.308 & 0.086 & -0.164 & 0.369 & -0.213 & 0.242 & -0.095 & 0.603 & -0.292 & 0.105 & $\begin{array}{l}- \\
-0.287\end{array}$ & 0.111 & -0.223 & 0.220 & -0.122 \\
\hline $\begin{array}{l}\text { Vessel } \\
\text { diameter/ } \\
\text { Tumor } \\
\text { diameter }\end{array}$ & -0.135 & 0.462 & -0.006 & 0.975 & -0.054 & 0.767 & 0.236 & 0.194 & -0.124 & 0.500 & 0.177 & 0.332 & -0.046 & 0.803 & 0.312 \\
\hline
\end{tabular}

*means that $\mathrm{P} \otimes 0.05$, with statistical significance.

\section{Correlation between microvascular parameters and DWC}

The correlations between the WCD indicators and microvessel parameters were exhibited in Table 5 and Fig. $1-3 . T^{2}$ The $W C D_{1}, W C D_{2}$, and $N W C D_{2}$ correlated positively with the MVD of RCC (Spearman rank correlation coefficients, all $p<0.05$ ). And the correlation between the WCD ${ }_{1}$ and with MVD was higher than that between $W C D_{2}$ with MVD. Moreover, the correlation between the $\mathrm{NWCD}_{2}$ was lower than that between $W C D_{2}$ with $M V D$.

Table 5

Multiple linear regression results evaluating the correlation of microvessel parameters and DWC

\begin{tabular}{|c|c|c|c|c|c|c|c|c|c|c|c|c|}
\hline \multirow[t]{2}{*}{ Microvessel Parameters } & \multicolumn{2}{|l|}{$\mathrm{WCD}_{1}$} & \multicolumn{2}{|c|}{$\mathrm{NWCD}_{1}$} & \multicolumn{2}{|l|}{$\mathrm{WCD}_{2}$} & \multicolumn{2}{|c|}{$\mathrm{NWCD}_{2}$} & \multicolumn{2}{|l|}{$\mathrm{WCD}_{3}$} & \multicolumn{2}{|c|}{$\mathrm{NWCD}_{3}$} \\
\hline & $\mathbf{r}$ & $\begin{array}{l}P \\
\text { value }\end{array}$ & $r$ & $\begin{array}{l}P \\
\text { value }\end{array}$ & $\mathbf{r}$ & $\begin{array}{l}P \\
\text { value }\end{array}$ & $\mathbf{r}$ & P value & $\mathbf{r}$ & $P$ value & $\mathbf{r}$ & $P$ value \\
\hline MVD & 0.533 & $0.002^{*}$ & 0.197 & 0.281 & 0.509 & $0.003^{*}$ & 0.366 & $0.040^{\star}$ & 0.333 & 0.063 & 0.184 & 0.313 \\
\hline MVA & 0.445 & $0.011^{*}$ & 0.091 & 0.619 & 0.576 & $0.001 *$ & 0.401 & $0.023^{\star}$ & 0.491 & $0.004^{*}$ & 0.413 & $0.019 *$ \\
\hline Specific microvascular & 0.216 & 0.234 & 0.233 & 0.200 & 0.216 & 0.234 & 0.441 & 0.012 & 0.266 & 0.142 & 0.202 & 0.266 \\
\hline Microvascular grading & 0.220 & 0.225 & -0.027 & 0.883 & 0.268 & 0.138 & 0.520 & $0.002^{\star}$ & 0.397 & $0.025^{\star}$ & 0.476 & $0.006^{*}$ \\
\hline Vessel diameter & 0.273 & 0.130 & 0.249 & 0.169 & 0.326 & 0.069 & 0.432 & 0.013 & 0.243 & 0.180 & 0.271 & 0.134 \\
\hline Tumor diameter & -0.268 & 0.138 & -0.158 & 0.386 & -0.159 & 0.383 & 0.177 & 0.332 & 0.095 & 0.606 & 0.388 & $0.028^{*}$ \\
\hline $\begin{array}{l}\text { Vessel diameter/ Tumor } \\
\text { diameter }\end{array}$ & 0.301 & 0.094 & 0.309 & 0.085 & 0.255 & 0.159 & 0.126 & 0.490 & 0.052 & 0.779 & -0.067 & 0.714 \\
\hline
\end{tabular}

For $M V A$, the $W C D_{1}, W C D_{2}, N W C D_{2}, W C D_{3}$, and $N_{W C D}$ correlated positively with the MVA of RCC (Pearson or Spearman rank correlation coefficients, all $p<$ 0.05). According to the strength of association, the order is as follows: $W C D_{2}, W C D_{3}$ and $W C D_{1}$. The correlations between the WCD 2 and $W C D_{3}$ with $M V A$ were stronger than those between the $\mathrm{NWCD}_{2}$ and $\mathrm{NWCD}_{3}$ with MVA.

The $\mathrm{WCD}_{3}, \mathrm{NWCD}$, and $\mathrm{NWCD}_{3}$ correlated positively with the microvascular grading of RCC (Spearman rank correlation coefficients, all p<0.05). The correlation between the $\mathrm{WCD}_{3}$ with microvascular grading was weaker than that between the $\mathrm{NWCD}_{3}$ with microvascular grading. What's more, $\mathrm{DNWC}$, was moderately correlated with the vessel diameter (Spearman rank correlation coefficients, $p<0.05$ ).

\section{Correlation between microvascular parameters and DIC}

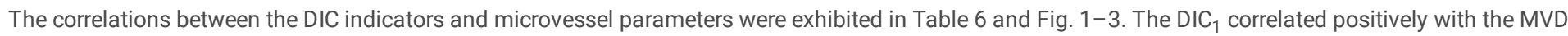
of RCC (Spearman rank correlation coefficients, $\mathrm{p}<0.05$ ). $\mathrm{NICD}_{2}$ and $\mathrm{NICD}_{3}$ correlated positively with the MVD of RCC (Spearman rank correlation coefficients, 
both $\mathrm{p}<0.05)$. The correlation between the $\mathrm{NICD}_{2}$ with microvascular grading $(r=0.397)$ was stronger than that between the $\mathrm{NICD}_{3}$ with microvascular grading $(r=0.383)$.

Table 6

Multiple linear regression results evaluating the correlation of microvessel parameters and DIC

\begin{tabular}{|c|c|c|c|c|c|c|c|c|c|c|c|c|}
\hline \multirow[t]{2}{*}{ Microvessel Parameters } & \multicolumn{2}{|l|}{$\mathrm{ICD}_{1}$} & \multicolumn{2}{|l|}{$\mathrm{NICD}_{1}$} & \multirow{2}{*}{$\begin{array}{l}\mathrm{DICD}_{2} \\
\mathbf{r}\end{array}$} & \multicolumn{2}{|c|}{$\mathrm{NICD}_{2}$} & \multicolumn{2}{|c|}{$\mathrm{ICD}_{3}$} & \multicolumn{2}{|c|}{$\mathrm{NICD}_{3}$} & \multirow[b]{2}{*}{$P$ value } \\
\hline & $\mathbf{r}$ & $\begin{array}{l}P \\
\text { value }\end{array}$ & $\mathbf{r}$ & $\begin{array}{l}\mathrm{P} \\
\text { value }\end{array}$ & & $\begin{array}{l}P \\
\text { value }\end{array}$ & $\mathbf{r}$ & $\begin{array}{l}\mathrm{P} \\
\text { value }\end{array}$ & $r$ & $P$ value & $\mathbf{r}$ & \\
\hline MVD & 0.473 & $0.006^{*}$ & 0.172 & 0.347 & 0.408 & 0.020 & 0.111 & 0.546 & 0.060 & 0.746 & 0.067 & 0.714 \\
\hline MVA & 0.398 & 0.024 & 0.017 & 0.925 & 0.540 & 0.001 & 0.225 & 0.215 & 0.427 & 0.015 & 0.243 & 0.180 \\
\hline Specific microvascular & 0.225 & 0.215 & 0.317 & 0.077 & 0.153 & 0.403 & 0.199 & 0.274 & -0.019 & 0.919 & 0.094 & 0.609 \\
\hline Microvascular grading & 0.217 & 0.233 & 0.187 & 0.305 & 0.234 & 0.197 & 0.397 & $0.024^{\star}$ & 0.190 & 0.298 & 0.383 & $0.030 *$ \\
\hline Vessel diameter & 0.211 & 0.246 & 0.162 & 0.375 & 0.227 & 0.212 & -0.035 & 0.849 & 0.025 & 0.890 & -0.084 & 0.648 \\
\hline Tumor diameter & -0.210 & 0.248 & 0.068 & 0.710 & -0.149 & 0.415 & -0.052 & 0.777 & -0.077 & 0.675 & -0.034 & 0.853 \\
\hline $\begin{array}{l}\text { Vessel diameter/ Tumor } \\
\text { diameter }\end{array}$ & 0.300 & 0.096 & 0.077 & 0.677 & 0.256 & 0.157 & -0.122 & 0.505 & -0.005 & 0.976 & -0.178 & 0.330 \\
\hline
\end{tabular}

*means that $\mathrm{P} \otimes 0.05$, with statistical significance.

\section{Discussion}

The incidence rate of RCC has increased in recent years, ranking seventh in the most frequently diagnosed malignancies[13]. Some renal cell carcinoma is one of the most hyper-vascularized tumors. Some renal cell carcinoma is one of the most vascularized tumors. High levels of HIF-1 and HIF-2 mediate the production of vascular endothelial growth factor (VEGF), which explains the high vascularization of RCC. Metabolic disorders and angiogenesis caused by hypoxia are the microenvironment basis of renal cell carcinoma metastasis. Angiogenesis is crucial for tumor growth and metastasis. The new microvessels in the tumor are the main sites for tumor cells to enter the circulation. The 5-year survival rate of metastatic renal cell carcinoma was less than $10 \%[14]$.

CT and MR perfusion to assess tumor angiogenesis. Nevertheless, perfusion parameters are not correlated to microvascular angiogenesis. Perfusion index (PI) reflects the ability of blood perfusion. The high PI of tumor tissue is not only related to the number of microvessels, but also related to that of large vessels. It may be for this reason that microvascular parameters such as MVD sometimes have no obvious correlation with CTP and MTP parameters. Nevertheless, due to the limitation of exam methods, the above opinions need to be supplemented by new means. The minimum voltage (80kvp) and the maximum voltage (140kvp) are usually used to achieve the maximum energy separation to distinguish different substances. Spectral CT scan quantitatively analyze the iodine and water density of RCC by generating decomposition image Spectral CT can be combined with iodine contrast to calculate iodine concentration in lesions. It can be used to evaluate the microvascular parameters including MVD, MVA and etc. al in various types of solid tumors.

In our study, iodine and water were used as the basis material pair in material decomposition and to measure IC and WC in kidney. The density of iodine and water in tumor can be quantitatively analyzed by spectral CT. In our study, the MVD, MVA and other microvascular parameters were evaluated on the basis of macroscopic imaging[15]. Only the mean IC, mean WC, mean NWC and mean NIC of renal cortex phase were positively correlated with MVD, suggesting that tumor cells were metabolized vigorously and blood supply was abundant, while there were no significant correlations between the above parameters and MVD in the other two phases. In the other two phases, the correlation between IC value and microvascular parameters is lower than that of cortical phase, which may be related to the blood flow characteristics of the kidney itself. In addition, RCC is rich in blood supply, so the IC of cortical phase can best reflect the real situation of microvessels. Some studies have convinced that the NIC value of enhanced CT scan was positively correlated with MVD[16]. A retrospective study of 60 patients with lung cancer showed that MVD was positively correlated with IC, ICD and NIC (range $0.581-0.800$, all < 0.001). Similar to our study, the correlation between IC and ICD and MVD is better than that between NIC and MVD. There was a certain amount of iodine in tumor tissue without injection of CT contrast agent. In addition, there is a mixture of different substances in the tissue, and the mixture of the two basic materials can be quantitatively measured by spectral CT. ICD can better eliminate these confounding factors. NIC usually refers to the ratio of IC in tumor to IC in thoracic aorta at the same level. It can be seen that NIC may also be affected by the degree of aortic enhancement when the blood supply of the subjects is different, which may also make NIC deviate from the actual IC of the lesion[17, 18]. It is believed that although angiogenesis is related to microvascular density, it does not necessarily lead to high blood flow, because the increased interstitial fluid pressure of immature and leaky new vessels may reduce blood flow and lead to tissue hypoxia[19].

IC mainly reflects the blood supply of microvascular RCC in the renal cortical phase, while IC may indicate the flow and retention of blood supply in the renal medullary phase. It is worth noting that cortical phase enhancement is more prominent in RCC, suggesting that cortical phase IC is more useful for the detection of angiogenesis in RCC. The IC of renal cortical phase image reflects the density of tumor capillaries, and the difference of renal cortical phase and medullary phase image reflects the clearance of tumor capillaries and tumor matrix[20]. In renal parenchymal phase, mean IC, mean NIC, random IC and random NIC had no significant correlation with microvascular parameters. lodine is the main component of CT contrast agent, so IC can effectively evaluate the blood supply of tumor. Given renal medulla is located in the deep layer of renal cortex, accounting for the vast majority of renal parenchyma, with few blood vessels. It is reasonable to explain that the indicators derived from IC are not related to microvascular conditions. 
In order to normalize the differences in individual circulation between patients, NIC and NWC were calculated. We found that the correlation between NIC and NWC with microvascular parameters was not significantly better than that of IC and WC. NIC and NWC did not show more stable as an index, which was slightly inconsistent with previous studies[21]. Some studies also suggest that NIC depends on the extent of lesion and aortic enhancement, and may make NIC deviate from the actual IC of lesion. This conclusion is similar to our result[17]. Therefore, in view of our findings in this study, IC may be a better indicator of tumor angiogenesis than NIC. When the RCC microvessels are relatively mature and the blood flow is fast, the contrast medium is easy to enter. In tumor tissue, when the differentiation degree of tumor is low, RCC grows fast, and the neovascularization structure is incomplete and unevenly distributed. These lesions show abnormal hemodynamics, resulting in uneven distribution of blood supply[22]. Therefore, in cortical and medullary phase, especially in cortical phase, NIC and NWC correlated with microvascular grading.

It has been shown that the average iodine density of larger tumors is significantly lower than that of the smaller ones[23], which is inconsistent with the results of our study. There was no significant correlation between derived parameters of IC and WC with tumor diameter except NWCD 3 . That is to say, in this study, the larger the tumor, the faster the water excretion, from the cortical phase to the renal pelvis secretory phase. The present study showed that in the difference between cortical phase and medullary phase as well as medullary phase, the correlation between WC derived indexes and angiogenesis seems to be more significant than that of IC derived indexes. This could be because with the increase of microvascular area and the complexity of microvascular structure, the water outflow from tumor tissue is more easily affected by the changes of microvascular structure[24]. In addition, the molecular weight of water is smaller than that of iodine compound, and the flow rate is faster. The change of WC in different phases can better represent the situation of microvessels.

Several limiting factors must be considered in this study. Firstly, the study included a relatively small number of RCC patients. We believe that our research may encourage future research, a large multicenter study will be desirable. Secondly, the relationship between the prognosis of these RCC patients and IC and WC is worth exploring. Moreover, although pathologists and radiologists are particularly careful in sampling, it is difficult to accurately match histopathological sections with imaging sections. RCCs may show different characteristics in different fields. In clinical practice, the ROI is delineated at the maximum level of axial and coronal tumor, and the average value of each measurement is calculated as the final result to minimize the systemic errors. Although strict inclusion and exclusion criteria were established, selection bias still existed due to the retrospective study. Further studies will be carried out with expanded samples. Finally, the correlation between WC and IC parameters on microvascular status is still in the research stage, and it needs to be further verified in the follow-up study before it can be applied in clinical practice.

\section{Conclusion}

In conclusion, Due to the objectivity and accuracy of spectral CT imaging, this study provides more objective and detailed information from a new perspective, thus contributing to the diagnosis and management of RCC.

\section{Abbreviations}

ccRCC $=$ Clear cell renal cell carcinoma

$\mathrm{IC}=$ lodine concentration

$I C D=$ lodine concentration difference

IVIM = Intravoxel incoherent motion

MVA = Microvascular area

MVD = Microvascular density

MIC = Mean iodine concentration

MNIC = Mean normalized iodine concentration

MNWC $=$ Mean normalized water concentration

$\mathrm{MWC}=$ Mean water concentration

$\mathrm{PI}=$ Perfusion index

$\mathrm{RCC}=$ Renal cell carcinoma

$\mathrm{RIC}=$ Random iodine concentration

$\mathrm{ROI}=$ Region of interest

RWC $=$ Random water concentration

NRIC = Normalized random iodine concentration

NRWC $=$ Normalized random water concentration 
$\mathrm{WC}=$ Water concentration

$W C D=$ Water concentration difference

\section{Declarations}

\section{Authors'contributions}

HXH and ZB designed the study idea. WQ and QX performed data mining. DXB and WJ performed data statistical analyses. LJ prepared figures and tables. ZB drafted the initial manuscript. SPF participated in the coordination of the study and reviewed the manuscript. HXH had primary responsibility for the final content. All authors have approved the final version of the manuscript.

\section{Funding information}

Not applicable.

\section{Availability of data and materials}

The datasets generated and/or analyzed during the current study are not publicly available due to the Personal Information Protection Act, but are available from the corresponding author upon reasonable request.

\section{Ethics approval and consent to participate}

We confirm that all methods were carried out in accordance with relevant guidelines and regulations. This study was approved by the Institutional Ethics Committee of the First Hospital of Jilin University, Changchun, China. Written informed consent was obtained from the patients by email or letter.

\section{Consent for publication}

Not applicable.

\section{Competing interests}

The authors have no conflicts of interest or potential conflicts of interest relevant to this article to disclose.

\section{References}

1. Hemminki K, Jiang Y, Ma X, Yang K, Egevad L, Lindblad P. Molecular epidemiology of VHL gene mutations in renal cell carcinoma patients: relation to dietary and other factors. Carcinogenesis. 2002;23:809-15.

2. Hötker AM, Karlo CA, Di Paolo PL, Zheng J, Moskowitz CS, Russo P, Hricak H, Akin O. Renal cell carcinoma: Associations between tumor imaging features and epidemiological risk factors. Eur J Radiol. 2020;129:109096.

3. Weng S, DiNatale RG, Silagy A, Mano R, Attalla K, Kashani M, Weiss K, Benfante NE, Winer AG, Coleman JA, Reuter VE, Russo P, Reznik E, Tickoo SK, Hakimi AA. The Clinicopathologic and Molecular Landscape of Clear Cell Papillary Renal Cell Carcinoma: Implications in Diagnosis and Management. Eur Urol. 2020.

4. Sopo M, Anttila M, Muukkonen OT, YIÄ-Herttuala S, Kosma VM, Keski-Nisula L, Sallinen H. Microvessels in Epithelial Ovarian Tumors: High Microvessel Density Is a Significant Feature of Malignant Ovarian Tumors. Anticancer Res. 2020;40:6923-31.

5. Manoharan D, Netaji A, Das CJ, Sharma S. lodine Parameters in Triple-Bolus Dual-Energy CT Correlate With Perfusion CT Biomarkers of Angiogenesis in Renal Cell Carcinoma. AJR Am J Roentgenol. 2020;214:808-16.

6. Zhang C, Wang N, Su X, Li K, Yu D, Ouyang A. FORCE dual-energy CT in pathological grading of clear cell renal cell carcinoma. Oncol Lett. 2019;18:640512.

7. Marcon J, Graser A, Horst D, Casuscelli J, Spek A, Stief CG, Reiser MF, Rübenthaler J, Buchner A, Staehler M. Papillary vs clear cell renal cell carcinoma. Differentiation and grading by iodine concentration using DECT-correlation with microvascular density. Eur Radiol. 2020;30:1-10.

8. Mayer P, Fritz F, Koell M, Skornitzke S, Bergmann F, Gaida MM, Hackert T, Maier-Hein K, Laun FB, Kauczor HU, Grenacher L, Klauß M, Stiller W. Assessment of tissue perfusion of pancreatic cancer as potential imaging biomarker by means of Intravoxel incoherent motion MRI and CT perfusion: correlation with histological microvessel density as ground truth. Cancer Imaging. 2021;21:13.

9. Udare A, Walker D, Krishna S, Chatelain R, Mclnnes MD, Flood TA, Schieda N. Characterization of clear cell renal cell carcinoma and other renal tumors: evaluation of dual-energy CT using material-specific iodine and fat imaging. Eur Radiol. 2020;30:2091-102.

10. Manoharan D, Netaji A, Diwan K, Sharma S. Normalized Dual-Energy lodine Ratio Best Differentiates Renal Cell Carcinoma Subtypes Among Quantitative Imaging Biomarkers From Perfusion CT and Dual-Energy CT. AJR Am J Roentgenol. 2020;215:1389-97.

11. Wang D, Huang X, Bai L, Zhang X, Wei J, Zhou J. Differential diagnosis of chromophobe renal cell carcinoma and papillary renal cell carcinoma with dualenergy spectral computed tomography. Acta Radiol. 2020;61:1562-9.

12. Ljungberg B, Albiges L, Abu-Ghanem Y, Bensalah K, Dabestani S, Fernández-Pello S, Giles RH, Hofmann F, Hora M, Kuczyk MA, Kuusk T, Lam TB, Marconi L, Merseburger AS, Powles T, Staehler M, Tahbaz R, Volpe A, Bex A. European Association of Urology Guidelines on Renal Cell Carcinoma: The 2019 Update. Eur Urol. 2019;75:799-810. 
13. Simonaggio A, Epaillard N, Pobel C, Moreira M, Oudard S, Vano YA. Tumor Microenvironment Features as Predictive Biomarkers of Response to Immune Checkpoint Inhibitors (ICl) in Metastatic Clear Cell Renal Cell Carcinoma (mccRCC). Cancers (Basel). 2021;13.

14. Ma W, Yang J, Liu N, Pu X, Qu F, Xu L, Zhao X, Li X, Zhang G, Guo H, Li D, Gan W. Are tumor-associated micro-angiogenesis and lymphangiogenesis considered as the novel prognostic factors for patients with Xp11.2 translocation renal cell carcinoma. BMC Cancer. 2020;20:1182.

15. Wu F, Zhou H, Li F, Wang JT, Ai T. Spectral CT Imaging of Lung Cancer: Quantitative Analysis of Spectral Parameters and Their Correlation with Tumor Characteristics. Acad Radiol. 2018;25:1398-404.

16. Li R, Li J, Wang X, Liang P, Gao J. Detection of gastric cancer and its histological type based on iodine concentration in spectral CT. Cancer Imaging. 2018;18:42.

17. Li Q, Li X, Li XY, Huo JW, Lv FJ, Luo TY. Spectral CT in Lung Cancer: Usefulness of lodine Concentration for Evaluation of Tumor Angiogenesis and Prognosis. AJR Am J Roentgenol. 2020;215:595-602.

18. Chen X, Ren K, Liang P, Li J, Chen K, Gao J. Association between spectral computed tomography images and clinicopathological features in advanced gastric adenocarcinoma. Oncol Lett. 2017;14:6664-70.

19. Yang DM, Palma DA, Kwan K, Louie AV, Malthaner R, Fortin D, Rodrigues GB, Yaremko BP, Laba J, Gaede S, Warner A, Inculet R, Lee TY. Predicting pathological complete response (pCR) after stereotactic ablative radiation therapy (SABR) of lung cancer using quantitative dynamic [(18)F]FDG PET and CT perfusion: a prospective exploratory clinical study. Radiat Oncol. 2021;16:11.

20. Yang CB, Yu N, Jian YJ, Yu Y, Duan HF, Zhang XR, Ma GM, Guo Y, Duan X. Spectral CT Imaging in the Differential Diagnosis of Small Bowel Adenocarcinoma From Primary Small Intestinal Lymphoma. Acad Radiol. 2019;26:878-84.

21. Cao Y, Zhang G, Bao H, Zhang S, Zhang J, Zhao Z, Zhang W, Li W, Yan X, Zhou J. Development of a dual-energy spectral CT based nomogram for the preoperative discrimination of mutated and wild-type KRAS in patients with colorectal cancer. Clin Imaging. 2021;69:205-12.

22. Wei J, Zhao J, Zhang X, Wang D, Zhang W, Wang Z, Zhou J. Analysis of dual energy spectral CT and pathological grading of clear cell renal cell carcinoma (ccRCC). PLoS One. 2018;13:e0195699.

23. Lennartz S, Täger P, Zopfs D, luga Al, Reimer RP, Zäske C, Große Hokamp N, Maintz D, Heidenreich A, Drzezga A, Kobe C, Persigehl T. Lymph Node Assessment in Prostate Cancer: Evaluation of lodine Quantification With Spectral Detector CT in Correlation to PSMA PET/CT. Clin Nucl Med. 2021;46:303-9.

24. Li Q, Li X, Li XY, He XQ, Chu ZG, Luo TY. Histological subtypes of solid-dominant invasive lung adenocarcinoma: differentiation using dual-energy spectral CT. Clin Radiol. 2021;76:77.e1-77.e7.

\section{Figures}

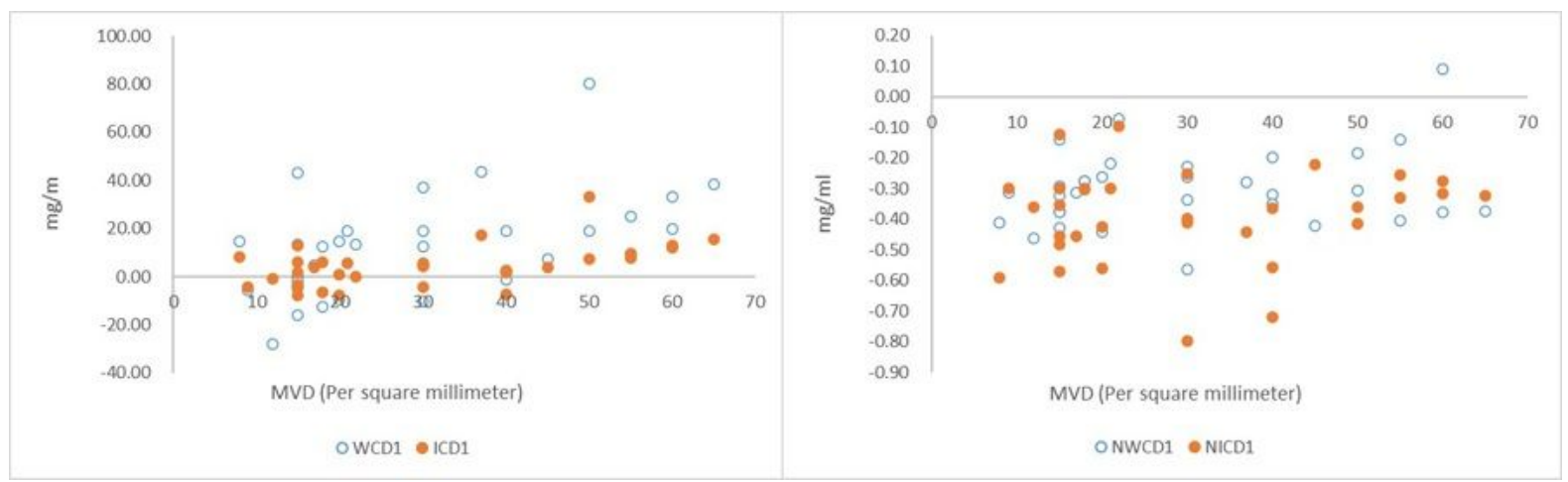

\section{Figure 1}

The relationship between WCD1, ICD1 and MVD in thirty-two RCC patients was set out. The relationship between NWCD1, NICD1 and MVD was also shown for comparison.

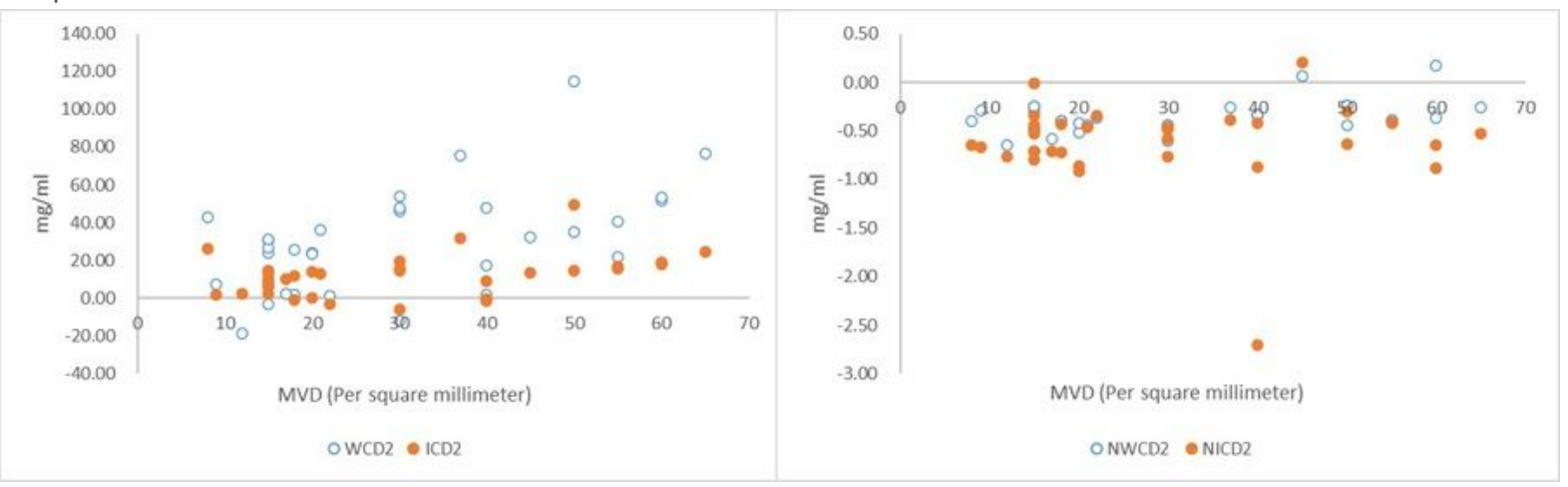

Figure 2 
The relationship between WCD2, ICD2 and MVD in thirty-two RCC patients was set out. The relationship between NWCD2, NICD2 and MVD was also shown for comparison.

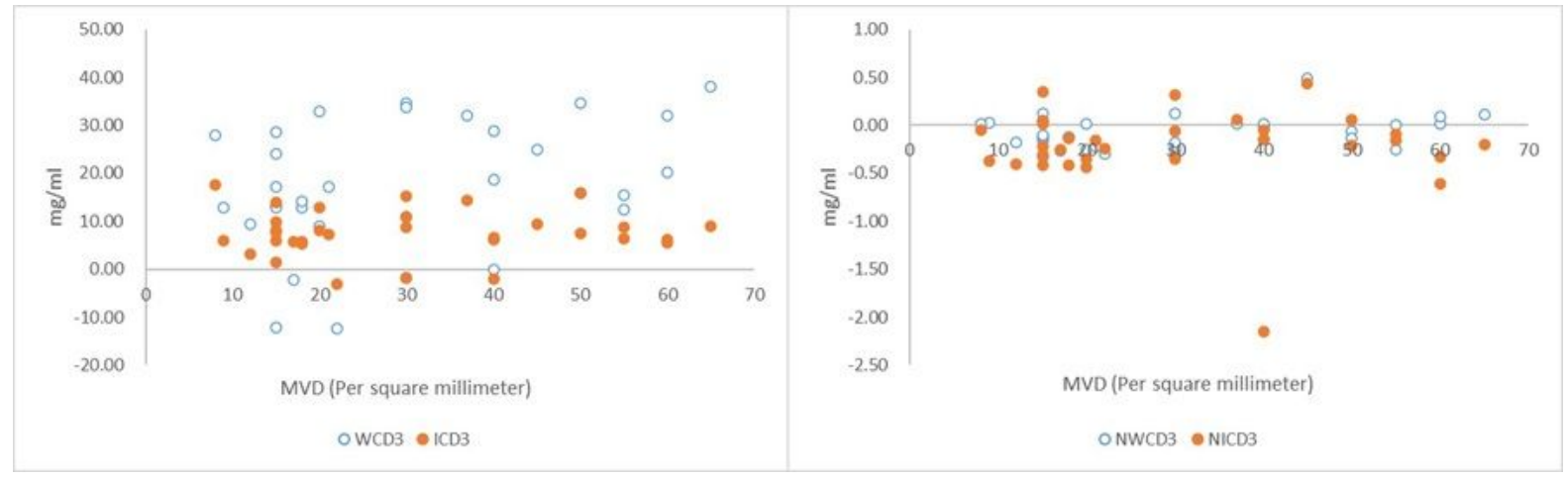

\section{Figure 3}

The relationship between WCD3, ICD3 and MVD in thirty-two RCC patients was set out. The relationship between NWCD3, NICD3 and MVD was also shown for comparison. 